\title{
The use of thermal manikin to evaluate interface pressure distribution
}

\author{
Flavia Renata Dantas Alves Silva Ciaccia, ${ }^{\mathrm{a},}$, Clenilson JordãoGonçalves ${ }^{\mathrm{b}}$ and Laerte Idal Sznelwar ${ }^{\mathrm{a}}$ \\ ${ }^{a}$ Department of Production Engineering, School of Engineering-University of São Paulo, Avenida Prof. Almeida \\ Prado, travessa 2, $n^{\circ}$ 128,05508-070 - Cidade Universitária - São Paulo/SP, Brazil. \\ ${ }^{\mathrm{b}}$ Embraer S.A., São José dos Campos, Brazil.
}

\begin{abstract}
The use of a thermal buttocks manikin ${ }^{1}$ was explored as a tool to standardize the evaluation of seat comfort. Thermal manikin buttocks were developed and calibrated thermally and anatomically to simulate the sensible heat transfer of a seated person and used to evaluate interface pressure distribution. In essence, the pressure maps of manikin buttocks with and without heating were compared to those of a seated person. The results of average pressure demonstrated that the thermal manikins have a better response in interface pressure measurement than manikins without heating.
\end{abstract}

Keywords: heat flow, buttock model, comfort

\section{Introduction}

Over the past 40 years, passenger comfort has been well studied in different means of transportation [11]. Considering that passengers are seated most of the time on a flight, the passenger seat has an important role to play in meeting the passenger's comfort expectations [14]. According to de Looze et al. (2003), the interface pressure distribution between an occupant and a seat appears as the objective measure with the clearest association with the subjective evaluation of seat comfort. Several studies in the literature suggest that the poor distribution of interface pressure between seat and occupant can lead to discomfort in the sitting posture $[3,7,8-10]$. This is because a high surface pressure can compress the blood vessels in tissues, restricting circulation and causing discomfort. Usually, seat evaluations using pressure mapping techniques are performed by subjects with different anthropometric characteristics.

However, previous studies show that one alternative approach to assess seat comfort is to use manikins representing the human anatomy. Standardized test methods for assessing the characteristics of seat cushions typically use buttocks models to achieve the necessary inter laboratory repeatability $[5,8,12]$.

Pipkin and Sprigle (2008) used two buttocks models made of different materials to analyze seven wheelchair cushions and four pressure mats according to their influence on the pressure magnitude, envelopment and immersion. One model was rigid and made of wood and the other was made of thermoplastic with embedded rigid cylinders to represent the ischial tuberosities. They concluded that the pressure mat attempted to take the shape of the indenter, but some folding or bending occurred. When the gel model was used, the pressure magnitude was not significantly different from the no-mat condition. On the other hand, pressure magnitude dropped significantly when the rigid model was used.

Besides the material and geometry of the manikin, some studies also consider the influence the bodysupport surface microclimate [5,6]. According to Fanger (1972), the temperature of the human body core is approximately $37^{\circ} \mathrm{C}$ and skin temperature is $34.1^{\circ} \mathrm{C}$ under conditions of thermal neutrality in se-

\footnotetext{
* Corresponding author. E-mail: fla_silva@hotmail.com

${ }^{1}$ The presented data were collected in a study entitled "Cabin Comfort - Integrated Analysis and Development of Criteria for Comfort", which has been development through a partnership between Embraer S.A. and Fundação de Amparo a Pesquisa do Estado de São Paulo (FAPESP), having the following universities USP, UFSCar and UFSC as collaborators.
} 
dentary activity without action by the thermoregulatory system. When the boundary conditions of the body tend to move out of the adequate temperature range, it increases the occupant thermal discomfort feeling of such ambient. For non-homogeneous ambient evaluation, where different body parts experience different thermal conditions such as cars and aircraft interiors, the equivalent temperature is defined as the uniform temperature of an imaginary ambient with air velocity equals to zero, in which people exchange the same amount of sensible heat by radiation and convection as in the real ambient, evaluated for each body part [1].

Considering the influence of the seat on the occupant comfort for non-homogeneous ambient, Zhang et al (2007) showed that the control of the heat flow and temperature of the seats may improve the acceptability of the thermal ambient. Fergunson-Pell et al. (2009) reported an apparatus and method for measuring the heat and moisture dissipation of wheelchair cushions under simulated loading conditions with a rigid buttock-shaped indenter. The heat and moisture output of the buttock-shaped indenter has been designed to simulate the sensible and insensible output of the human body under testing conditions. The test results demonstrated that an acceptable level of repeatability can be achieved with this system with a 95 percent confidence interval of $\pm 1^{\circ}$ (coefficient of variation [CV] of $4.4 \%$ ) for the interface temperature after $1 \mathrm{~h}$ and \pm 3 percent $\mathrm{RH}$ (CV of 7.1\%) for the associated level of humidity.

Although anatomically shaped systems have been developed for measuring the heat and water vapor dissipation, Gonçalves (2010) verified that thermal manikins could be useful in interface pressure measurement. His research investigated the heat transfer characteristics at the interface between seat and subject using a thermal manikin and verified that the interface pressure directly depends on the local heat flow. Furthermore, it was verified that the changes on the heat flow caused by passenger metabolism modifications are inversely proportional to the seat global thermal resistance and that modifications on the seat pressure distribution due to the weight increase or decrease are directly proportional to the seat global thermal resistance, i.e., the lower the weight of the passenger, the lower the seat global thermal resistance.

The present study explored the use of thermal manikin buttocks as a tool to standardize the evaluation of seat comfort. A manikin was developed and calibrated thermally and anatomically to simulate the sensible heat transfer of a seated person and used to evaluate interface pressure distribution. In essence, the pressure maps of manikin buttocks with and without heating were compared to those of a seated person.

\section{Method}

\subsection{Apparatus}

The focus of the present study was the interface pressure between the occupant and the seat bottom cushion, represented only by the occupant's buttocks and thighs. The thermal manikin buttocks were designed by Gonçalves (2010) to simulate the seat occupant thermally and ergonomically, respectively defined by heat flow and surface temperature, and pressure distribution between the passenger and the seat.

An economy class aircraft seat was selected as a reference for the experiments. The thermal manikin buttocks were molded from a male subject $95 \%$ percentile on this aircraft passenger seat by means of thermo-plastic material. Figure 1 illustrates the male subject during the modeling process and the final shape of the thermal manikin buttocks.
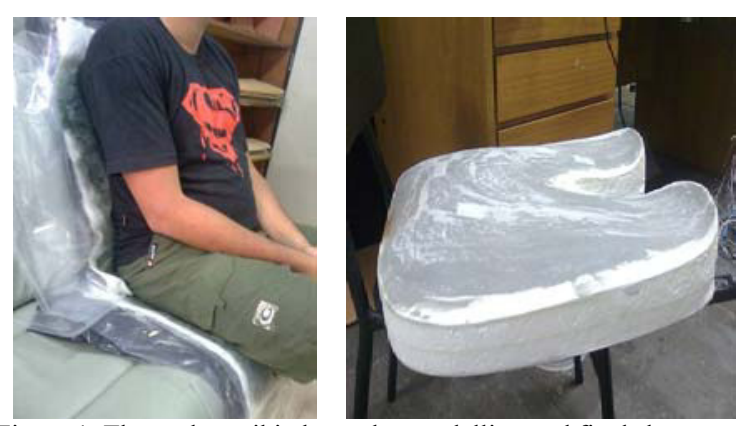

Figure 1. Thermal manikin buttocks: modelling and final shape

The occupant's body temperature was simulated using electrical heaters installed on the surface of the buttock model. The estimated maximum power dissipated by the person to the seat is $120 \mathrm{~W} / \mathrm{m}^{2}$, so this value was used for the heaters sizing.

The experiments were conducted on a seat equipped with a pressure mat on the bottom cushion (model X3 PX100: $50.8 \mathrm{~cm} \times 81.28 \mathrm{~cm} 40.64 .02$ Xsensor). In order to simulate the interface pressure distribution of the occupant and the seat, lead weights were placed on the base of the thermal buttock manikin, according to Figure 2. 

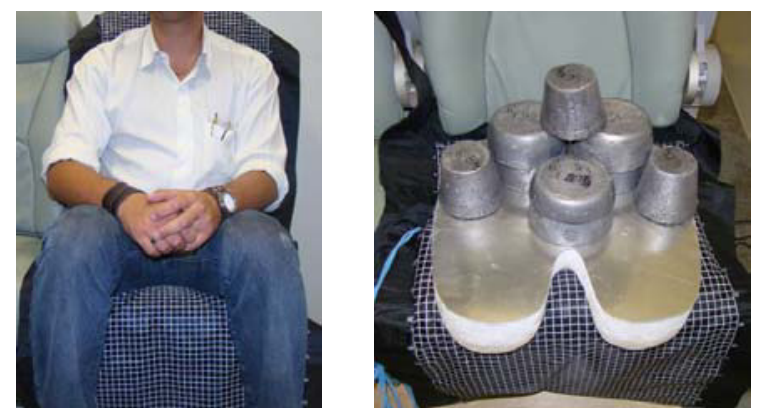

Figure 2. Pressure distribution measurement: subject and thermal manikin buttocks

\subsection{Experimental protocol}

The first part of the experiment evaluated the buttock manikin with heating. The thermal buttock model with the heating system turned on was positioned on the seat and remained in the same position for 3 hours. The duration of the experiment was chosen considering the maximum period of use of the pressure mapping equipment according to the manufacturer. After that, the apparatus was dismantled in order to lighten the load on the seat foam. Only the next day was the second part of the experiment carried out: the test was repeated without turning the heating system on.

The pressure map of the male subject $95 \%$ percentile was also recorded. Unfortunately, it was not possible to maintain the subject for 3 hours in the same position. Therefore, the subject was requested to stay for 10 minutes seated without moving, as can be seen in Figure 2.

\section{Results}

To verify the influence of the thermal manikin buttocks heating in the interface pressure, the values of average pressure and the contact area were considered. Table 1 shows the average values for pressure and contact area. The peak pressure values were not used due to the lack of stability already demonstrated in other studies in the literature $[12,13]$.

Table1. Values of average pressure and contact area

\begin{tabular}{|l|c|c|c|}
\hline Magnitude & $\begin{array}{c}\text { Male } \\
\text { Subject }\end{array}$ & $\begin{array}{c}\text { Manikin without } \\
\text { Heating }\end{array}$ & $\begin{array}{c}\text { Manikin with } \\
\text { Heating }\end{array}$ \\
\hline Average Pressure $(\mathrm{mmHg})$ & 39.95 & 27.65 & 31.51 \\
\hline Contact Area $\left(\mathrm{in}^{\wedge} 2\right)$ & 214.84 & 193.02 & 194.45 \\
\hline
\end{tabular}

\subsection{Average pressure}

Comparing the average pressure per time of the first 10 minutes of the experiment for thermal manikin buttocks turned on and off, it was possible to notice that they follow the same trend as the experiment conducted with the male subject (see Figure 3). The values of average pressure with the manikin using the heating system turned on were closer to the results of the experiments performed by the subject. The average values of pressure were $12 \%$ higher in the experiment using heating than without heating.

From the data collected, the average pressure of male subject experiment was $21 \%$ higher than the experiment using thermal manikin buttocks with heating system turned on.

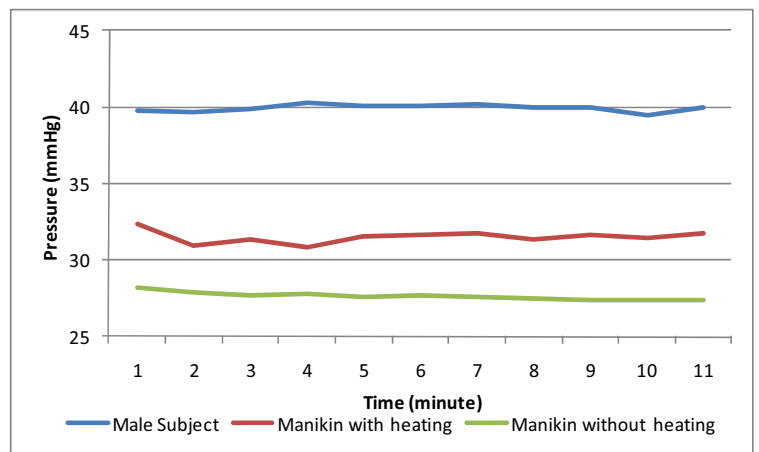

Figure 3. Average pressure versus time

\subsection{Contact area}

The values of contact area during the first $10 \mathrm{mi}$ nutes of the experiments showed that the curve of thermal manikin without heating system turned on followed the same trend as the male subject curve, as can be seen in Figure 4. On the other hand, the curve of the thermal manikin with heating on showed instability. On average, the values of the contact area for the male subject were $10 \%$ higher than the values of the thermal manikin without heating system turned on. 


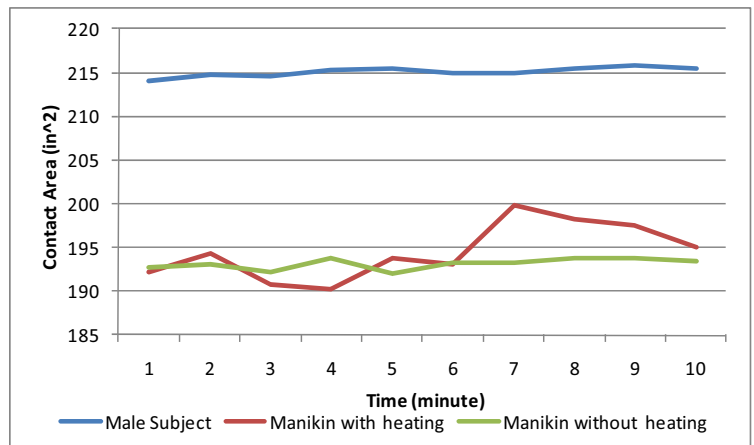

Figure 4. Contact area versus time

\subsection{Pressure maps}

Figure 5 illustrates the average pressure maps for male subject, manikin with and without heating system turned on. Observing the interface contour, it is possible to distinguish the difference caused by the heating system. The regions with higher load became even more loaded.

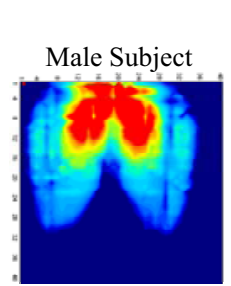

Manikin without
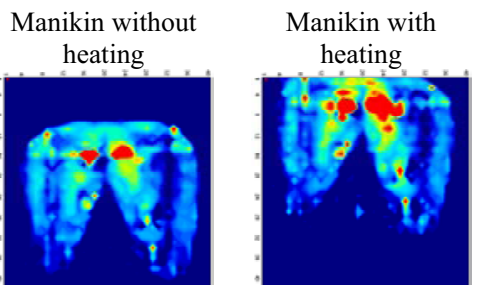

Figure 5. Pressure maps

\section{Discussion}

The objective of this study was to investigate the use of thermal manikin in evaluations of seat comfort, comparing the results of experiments using this manikin with heating and without heating. The results showed that thermal manikin buttocks are suitable for thermal simulation of a seated person and that it can be used to estimate interface pressure distribution. Although, improvements could be implemented in the manikin in order to better represent the human body contour and weight distribution.

The results of average pressure demonstrated that the thermal manikins have a better response in interface pressure measurement than manikins without heating. This difference can be explained by the physiological aspects of the buttock region, such as blood pressure in the capillaries and arteries and their influence in interface pressure.
From the data collected with the calibrated thermal manikin, it was concluded that the calculated uncertainty for the evaluations performed with the thermal manikin is $21 \%$ as compared to the interface pressure for the male subject. The contour of the pressure maps shows that there is room to improve the loading mechanism of the manikin in order to obtain a more realistic pressure distribution. In fact, this thermal manikin was developed to assess thermal comfort and here it was used to evaluate interface pressure, explaining the low fidelity to the human body contour. As a suggestion for future studies, thermal manikins with more flexible materials, similar to the human body composition, could be developed .

One of the advantages of using thermal manikins is to standardize the evaluation of seat comfort without the need of using the same subjects in all the experiments. It also permits to compare the results of interface pressure distribution of different seats without depending on real subjects. The methodology used is adequate for optimization of the seats design because it can improve the repeatability and reproducibility of experiments and also reduce cost and time of developing a new seat.

On the other hand, experiments using a manikin have some limitations. The manikin is a model based on an unique percentile and it does not represent the anthropometric characteristics of the entire user population. Besides, the experiments are usually static evaluations that do not take into account the variety of activities that can be performed in a seat.

In conclusion, the use of manikins in seating comfort evaluations does not replace the subjective analysis, but rather complements it.

\section{References}

[1] ASHRAE 62.1, Ventilation for Acceptable Indoor Air Quality American Society of Heating, Refrigerating and Air Conditioning Engineers Inc. Atlanta, 2004.

[2] de Looze, M.P., Kuijt-Evers, L.F.M.; van Diee, N, J. Sitting comfort and discomfort and the relationship with objective measures. Ergonomics, v.46, p.985 - 997, 2003.

[3] Dhingra, H.S.; Tewari, V.K.; Singh, S. Discomfort, Pressure Distribution and Safety in Operator's Seat - A Critical Review Agricultural Engineering International: the CIGR Journal of Scientific Research and Development. v. V, 2003.

[4] Fanger, P. O. Thermal Comfort Analysis and Applications in Ambiental Engineering, McGraw-Hill, New York, 244 p., 1972.

[5] Ferguson-Pell, M.; Hirose, H.; Nicholson, G.; Call, E. Thermodynamic rigid cushion loading indenter: a buttock-shaped temperature and humidity measurement system for cushioning surfaces under anatomical compression conditions. Journal of 
Rehabilitation Research \& Development. v. 46, n.7, p.945-56. 2009.

[6] Gonçalves, C. J. Estudo Experimental da troca de calor entre o passageiro e o banco de veículos utilizando manequim instrumentado. Master Thesis.University of São Paulo, Brasil. 2010 .

[7] Goonetilleke, R.S.; Feizhou, S. A methodology to determine the optimum seat depth. International Journal of Industrial Ergonomics, Hong Kong, 27, pp 207-217, 2001.

[8] [1] International Organization for Standardization (ISO). Wheelchair seating-Part 2: Determination of physical and mechanical characteristics of devices intended to manage tissue integrity-Seat cushions. Geneva (Switzerland): ISO; 2007. Report No.: ISO 16840-2:2007.

[9] Moes, N.C.C.M. Pressure Distribution and Ergonomics Shape Conceitualization. In:International Design Conference, 2000, Dubrovnik.

[10]Noro, K. Fujimaki, G,; Kishi, S. A theory on pressure distribution and seat discomfort. In VINK, P. Comfort and design: principles and good practice. Florida, CRC Press, 2005.
[11] Oborne, D.J. Techniques available for the assessment of passenger comfort. Applied Ergonomics, v.9, n.1, p.45-49. 1978.

[12]Pipkin, L.; Sprigle, S. Effect of model design, cushion construction, and interface pressure mats on interface pressure and immersion. Journal of rehabilitation research \& development, v.45, n.6, 2008.

[13] Sprigle S, Dunlop W, Press L. Reliability of bench tests of interface pressure. Assistive Technology. v.15, n.1, p.49-57, 2003.

[14] Tan, C.F.; Chen, W.; Rauterberg, M. Development of adaptive aircraft passenger seat system for comfort improvement. International Conference for Technical Postgraduates, Kuala Lumpur, Malaysia, paper no. CC02-05, 14-15 December 2009.

[15]Zhang, Z., Chen, X., Mazundar, S., Zhang, T., Chen, Q. Experimental and numerical Investigation of airflow and Contaminant transport in an airliner cabin mock-up. Proceedings of the 10th International Conference on Air Distribution in Rooms Roomvent 2007. Helsinki, 2007. 